\title{
PEMBERIAN AROMATHERAPY LAVENDER PADA IBU BERSALIN KALA I FASE AKTIF UNTUK MENGURANGI KECEMASAN DI RB PUTRI ASIH PEKANBARU
} TAHUN 2019

\author{
RIKA ANDRIYANI, VEREN THERESIA
}

STIKes HANG TUAH PEKANBARU

\begin{abstract}
The first stage of labor is the opening period which lasts 8-13 hours. During the first stage psychological disorders cannot be avoided, namely in the form of anxiety. Anxiety is a physical, mental, chemical reaction of the body to situations that are frightening, shocking, confusing, dangerous, worrying someone due to excessive levels of catecholamines. The impact of anxiety that occurs during childbirth is disruption of uterine contractions, decreased blood flow to the placenta, reduced oxygen available to the fetus and can increase the length of the period I. One way to reduce anxiety in childbirth is the provision of aromaterapy, especially lavender aromaterapy, which is a beneficial therapeutic action. improve the physical and psychological condition of the mother in labor. Objective: to carry out midwifery care for mothers during the active phase of labor by giving lavender aromaterapy to reduce anxiety. The method used was a case study and the case study was carried out by the report at RB Putri Asih Pekanbaru city. Care starts from assessment to enforce $d x$, namely G3P2AO Parturien Aterm during the active phase with anxiety. Single live fetus, prescription. Mother's anxiety is resolved by giving lavender aromaterapy. It is suggested to the leadership of the $R B$ to do lavender aromaterapy care for every patient giving birth.
\end{abstract}

Key word : Maternity, Aromaterpy Lavender, and Anxiety

\begin{abstract}
ABSTRAK
Kala I persalinan merupakan kala pembukaan yang berlangsung anatar 8- 13 jam. Selama kala I gangguan psikologis tidak dapat dihindari yakni berupa kecemasan. Kecemasan merupakan reaksi fisik, mental, kimiawi dari tubuh terhadap situasi yang menakutkan, mengejutkan, membinggungkan, membahayakan, merisaukan seseorang akibat kadar katekolamin yang berlebihan. Dampak kecemasan yang terjadi selama persalinan yakni tergannggunya kontraksi rahim, turunya aliran darah ke plasenta, berkurangnya oksigen yang tersedia untuk janin serta dapat meningkatkan lamanya kala I. Salah satu cara untuk menurunkan kecemasan dalam persalinan adalah pemberian aromaterapy khususnya aromaterapy lavender yang merupakan tindakan tarapeutik yang bermanfaat meningkatkan kondisi fisik dan psikologis ibu bersalin. Tujuan: melaksanakan asuhan kebidanan pada ibu bersalin kala I fase aktif dengan pemberian aromaterapy lavender untuk mengurangi kecemasan. Metode yang digunakan adalah studi kasus dan pengambilan kasus dilakukan Laporan di RB Putri Asih kota Pekanbaru. Asuhan dimulai dari pengkajian hingga menegakkan dx yakni G3P2A0 Parturien Aterm kala I fase aktif dengan cemas. Janin hidup tunggal, preskep. Kecemasan ibu teratasi dengan pemberian aromaterapy lavender. Disarankan kepada pimpinan RB agar dilakukan asuhan aromaterapy lavender setiap pasien bersalin.
\end{abstract}

\section{Kata Kunci $\quad$ : Bersalin, Aromaterpy Lavender, dan Kecemasan}




\section{PENDAHULUAN}

Persalinan merupakan serangkaian kejadian yang berakhir dengan pengeluaran bayi, plasenta, dan selaput ketuban. Persalinan terbagi menjadi beberapa tahapan yaitu kala I (pembukaan), kala II (pengeluaran janin), kala III (pengeluaran plasenta), kala IV (observasi). Dimana asuhan kebidanan sangat diperlukan pada proses kala I. Lamanya kala I untuk primigravida berlangsung 12 jam, sedangkan multigravida 8 jam. Pada ibu bersalin sering merasa cemas memikirkan hal-hal yang akan terjadi seperti perasaan sakit, dan takut. Dukungan psikologis dari orang-orang yang terdekat akan membantu memperlancar proses persalinan (Fatikhah, A. \& Setiyowati, 2012).

Persalinan normal dipengaruhi 4P + 1P, yaitu power (kekuatan mendorong janin keluar yang mencakup his/kekuatan uterus kontraksi otot dinding perut, kontraksi diafragma, dan ligamentum action dari ibu), passage (jalan lahir), passenger (janin dan plasenta), psychologic (psikologis ibu bersalin, kecemasan merupakan salah satu faktor psikologis yang memengaruhi ibu dalam persalinan) dan penolong (Difarissa, R.R., Tarigan, J. \& Hadi, 2016).

Menurut Danuatmaja dan Meiliasari dalam Rista menyatakan bahwa kecemasan dan ketakutan dapat menyebabkan rasa nyeri yang hebat dan juga dapat mengakibatkan menurunya kontraksi uterus, sehingga persalinan akan bertambah lama. Peneliti menunjukan bahwa nyeri persalinan khususnya kala I lebih banyak dirasakan pada primigravida yaitu sebesar 59,38\% sedangkan pada multigravida sebesar $40,62 \%$.

Oleh karena itu, diperlukan upaya untuk menangani nyeri saat persalinan. Upaya ini dapat dilakukan dengan metode farmakologis dan non farmakologis. Salah satu metode mengurangi kecemasan pada persalinan dengan mengunakan nonfarmakologis yaitu. Aromaterapy merupakan sistem penyembuhan yang melibatkan pemakaian minyak atsiri murni. Terapi non farmakologis ini bisa dilakukan dengan berbagai macam metode seperti pijat, semprotan, inhalasi, mandi, kumur, kompres dan juga pengharum ruangan. Akses aromaterapy melalui hidung (inhalasi) adalah rute yang jauh lebih cepat dibanding cara lain (Karlina, S.D., Reksohusodo, S. \& Widayati, 2014).

Aromaterapy lavender merupakan tindakan terapeutik yang bermanfaat meningkatkan kondisi fisik dan psikologis ibu bersalin. Secara fisik baik digunakan untuk mengurangi rasa nyeri, sedangkan secara psikologis dapat merilekskan pikiran, menurunkan ketegangan dan kecemasan serta meberi ketenangan 
(Karlina, S.D., Reksohusodo, S. \& Widayati, 2014).

Berdasarkan hasil penelitian yang dilakukan (Karlina, S.D., Reksohusodo, S. \& Widayati, 2014) dengan judul “ Pengaruh Pemberian Aromaterapy Lavender secara Inhalasi terhadap Penurunan Intensitas Nyeri Persalinan Fisiologis pada Primipara Inpartu Kala Satu Fase Aktif di BPM "Fetty Fathiyah" Kota Mataram". Hasil penelitian ini menunjukkan adanya perbedaan tingkat nyeri persalinan berdasarkan universal assesment pain tool antara sebelum diberikan aromaterapi (pretest) dengan setelah diberikan aromaterapi (posttest), yaitu sebelum diberikan intervensi (pretest) aromaterapi lavender, rata-rata intensitas nyeri yang dirasakan responden adalah 7,65 dengan rincian sebanyak 17 orang $(85 \%)$ merasakan nyeri berat, 3 orang (15\%) merasakan nyeri sedang, dan tidak ada yang merasakan nyeri ringan dan sangat berat (tidak terkontrol). Sementara setelah diberikan intervensi aromaterapi lavender (post test), rata-rata intensitas nyeri responden yaitu 4,65 dengan rincian sebanyak 1 orang $(5 \%)$ merasakan nyeri berat, 2 orang $(10 \%)$ merasakan nyeri ringan, 17 orang (85\%) merasakan nyeri sedang. Jadi dapat disimpulkan bahwa intensitas nyeri setelah diberikan aromaterapi lavender lebih rendah daripada intensitas nyeri sebelum diberikan aromaterapy lavender.

\section{METODE PENELITIAN}

Metode laporan ini adalah studi kasus dengan mengacu pada asuhan kebidanan pada ibu bersalin. Studi kasus ini menggambarkan asuhan kebidanan pada ibu bersalin dengan pemberian Aromaterapy Lavender untuk mengurangi kecemasan.

Instrumen yang digunakan berupa pengkajian pada ibu bersalin, alat pemeriksaan ( Aromaterapy Lavender, diffuser, air bersih, partus set, APD, patograf, alat TTV, cok sambung, meja).

\section{HASIL}

Kajian pertama dilakukan pada $\mathrm{Ny}$. F G3P2A0 Parturient kala I fase aktif tanggal 21 Juli 2019 pukul 13.30 WIB, data subjektif Ny. F usia 29 tahun, Ibu mengeluh nyeri pinggang menjalar keperut bagian bawah sejak pukul 10.30 wib Seperti yang dikatakan ibu “ Keluhannya pinggang nyeri dari jam 10.30 tadi, dan mules-mules, pusing, sering bak, susah tidur sejak semalam,. "saya susah tidur, karena mules mules yang mulai sering juga sering BAK”, Pada anamnesis selanjutnya ibu merasa khawatir dan membayangkan akan terjadinya hal-hal 
yang tidak diinginkan pada janin dan dirinya. "saya kahawatir bisa tidak ya saya melahirkan normal, mudah-mudahan tidak terjadi apa-apa dengan saya dan bayi saya” . Riwayat persalinan dan kehamilan yang lalu Ny F normal “ 2 anak saya sebelumnya semuanya lahir normal sehat tidak ada masalah kata bidannya". Ny F juga tidak memiliki riwayat penyakit yang diderita saat ini maupun riwayat penyakit keturunan dalam keluarga.

Pada pengumpulan data objektif ditemukan Keadaan umum ibu baik, keadaan emosional ibu cemas, muka pucat/tegang, gelisah, keringat berlebihan, tidak dapat diam, tanda-tanda vital (TD :100/ 60, P:29x/i, N:93x/i, S:36,4), TFU $33 \mathrm{~cm}$, PUKA Preskep, DJJ 148x/i, VT: pembukaan $3 \mathrm{~cm}$, Ketuban positif Hodge II. Dari hasil pengkajian data di atas dapat ditarik analisa Ny. F G3P2A0 aterm inpartu kala I fase aktif dengan kecemasan.

\section{PEMBAHASAN}

Pada penyusunan karya tulis ilmiah ini, penulis melakukan penelitian pada $\mathrm{Ny}$. F umur 29 tahun dengan memberikan aromaterapy lavender untuk mengurangi kecemasan di RB Putri Asih kota Pekanbaru. Pada data subjektif, ibu mengatakan mengeluhkan nyeri pinggang menjalar keperut bagian bawah dan mulesmules, pusing, sering bak, susah tidur sejak semalam, ibu khawatir dan membayangkan akan terjadinya hal-hal yang tidak diinginkan pada janin dan dirinya.. Hal ini sesuai dengan teori (Fitriana Yuni, 2018) yang mengatakan bahwa gejala-gejala ibu bersalin yang mengalami kecemasan yaitu seperti gemetaran, tegang, nyeri otot, gelisah, tidak dapat diam, susah tidur, sering bak, keringat berlebihan, dan rasa khawatir yang berlebihan tentang hal-hal yang akan datang sepeti cemas, takut, khawatir, dan membayangkan akan datangnya kemalangan terhadap dirinya dan janin. Oleh karena itu perlu melakukan sesuatu untuk mengatasi hal tersebut yaitu dengan memberikan aromaterapy lavender untuk mengurangi kecemasan pada ibu bersalin.

Pada pengkajian diatas dari data subjektif didapat bahwa ibu mengatakan rasa cemasnya berkurang setelah pemberian aromaterapy lavender. Hal ini sesuai dengan teori ( Karlina, S.D., Reksohusodo, S. \& Widayati, 2014) yang mengatakan bahwa aromaterapy lavender merupakan tindakan tarapeutik yang bermanfaat meningkatkan kondisi fisik dan psikologis ibu bersalin. Secara fisik baik digunakan untuk mengurangi rasa nyeri, sedangkan secara psikologis dapat merilekskan pikiran, menurunkan ketegangan dan kecemasan serta memberi ketenangan. Dari data objektif diatas menunjukan keselarasan sesuai dengan teori (Simpkin, 2009) yaitu Ny F yang 
mengalami nafas cepat, nadi meningkat, muka pucat/ tegang, gelisah, keringat berlebihan, tidak dapat diam. Berdasarkan hasil pemeriksaan fisik atau yang lainnya berjalan dengan normal.

Diagnoasa yang dapat ditegakkan pada asuhan kebidanan ini adalah Berdasarkan dari penilitian yang telah dilakukan, peneliti dapat menilai bahwa Ny. F mengalami masalah dalam masa bersalin yaitu kecemasan menurut teori ( Trirestuti, C. \& Puspitasari, 2018)

Penatalaksanaan atau asuhan yang diberikan terhadap Ny. F dengan memberikan aromaterapy lavender untuk mengurangi kecemasan. Planning pada kasus ini pertama kali penulis membanggun hubungan baik dengan klien, meminta persetujuan kepada ibu untuk menjadi responden dalam penelitian ini dan memberitahu hasil pemeriksaan kepada ibu. Setelah mendapatkan persetujuan pasien, penulis melakukan asuhan sayang ibu dan pemberian aromaterapy lavender selama 10-15 menit dengan cara dihirup menggunakan diffuser dan memberikan Penkes tentang psikologis kepada ibu yaitu memberikan informasi tentang persalinan normal dan asuhan rutin pada kala I. Setelah dilakukan asuhan kebidanan selama 10-15 menit kepada pasien maka hasil yang didapatkan pada kajian ini yaitu perasaan cemas yang di alami ibu berkurang.
Asuhan diatas sesuai dengan teori yang disampaikan oleh (Husny, 2009) salah satu untuk menurunkan kecemasan adalah dengan pemberian aromaterapy. Beberapa peneliti menunjukan bahwa dengan mengunakan inhalasi pada aromaterapy mampu menurunkan tingkat kecemasan seseorang terutama pada aromaterpy lavender. Dampak positif aromaterpy terhadap penurunan tingkat kecemasan disebabkan karena aromaterpy diberikan secara langsung (inhalasi). Mekanisme melalui penciuman jauh lebih cepat dibanding rute yang lain dalam penanggulangan problem emosional seperti stres dan kecemasan, termasuk sakit kepala karena hidung/penciuman mempunyai kontak langsung dengan bagian-bagian otak yang bertugas merangsang terbentuknya efek yang ditimbulkan oleh aromaterpy.

\section{KESIMPULAN}

Asuhan kebidanan pada ibu bersalin di RB Putri Asih dilaksanakan menggunkan pendekatan dengan Pendokumentasian SOAP. Setelah mengumpulkan data secara keseluruhan pada ibu bersalin dapat diperoleh kesimpulan bahwa ibu dengan G3P2A0 Parturient aterm kala I fase Aktif, janin hidup tunggal, intrauteri, presentasi kepala, keadaan umum ibu cemas dan janin baik. Ibu Ny F dengan keadaan 
umum ibu cemas dan keadaan janin baik menghadapi proses kala I berajalan dengan baik meskipun pada saat pengkajian ibu merasa cemas, nyeri, muka pucat/tegang, gelisah, keringat berlebihan, tidak dapat diam nyeri, dan nafas lebih cepat serta nadi meningkat pada saat observasi, namun dapat di atasi dengan memberikan aromaterapy lavender dengan menggunakan diffuser selama 1015 menit pada kala I fase aktif dan memberi dukungan psikologis kepada $\mathrm{Ny}$ F. Selama pelaksanaan proses kala I, ibu dapat di ajak bekerja sama dengan baik sehingga proses kala I berjalan dengan baik lebih kurang lamanya proses kala I dari pembukaan $7 \mathrm{~cm}$ ke pembukaan lengkap adalah 40 menit

Dalam tindakan tatalaksana kasus telah diberikan sesuai dengan keluhan ibu dan ibu telah menerima dan memahami serta ibu melaksanakan anjuran yang telah diberikan.

\section{SARAN}

\section{Bagi RB Putri Asih Kota Pekanbaru}

Aromaterapy Lavender pada ibu bersalin kala I diharapkan dapat menjadi pertimbangan bagi bidan dan tenaga kesehatan lainnya khususnya yang berada di pelayanan RB Putri Asih untuk mempromosikan atau mensosialisasikan manfaat dari aromaterapy lavender pada ibu bersalin kala I. Dari hasil penelitian ini, aromaterpy lavender dapat dimasukan ke dalam intervensi sebagai salah satu cara yang diterapkan dalam menurunkan kecemasan pada ibu bersalin kala I.

\section{Bagi STIKes Hangtuah Pekanbaru}

Dengan mempertimbangkan hasil penelitian ini disarankan kepada institusi pendidikan agar dapat menambah sumbersumber buku tentang aromaterapy khususnya aromaterpy lavender yang baik digunakan pada ibu bersalin kala I, dan menyediakan alat untuk penelitian seperti diffuser dan minyak aromatery. Sehingga mahasiswa tidak kesulitan dalam mencari sumber dalam pembelajaran.

\section{Bagi Mahasiswa}

Diharapkan studi kasus ini dapat dijadikan pedoman atau informasi dan menambah pengetahuan penulis selanjutnya yang akan melakukan studi kasus yang serupa dan bahkan bisa melakukan studi kasus yang sama pada ibu bersalin.

\section{DAFTAR PUSTAKA}

Ayuningtyas, I. . (2019). Kebidanan Komplementer. (A. Savitri, Ed.). Yogyakarta: PT Pustaka Baru.

Difarissa, R.R., Tarigan, J. \& Hadi, D. P. (2016). Hubungan Tingkat Kecemasan dan Lama Partus Kala I Fase Aktif pada Primigravida, 2(3), $532-552$. 
Dwijayanti, W., Sumarni, S. \& Ariyanti, I. (2014). Efek Aromaterapy Lavender Inhalasi terhadap intesitas nyeri pasca sectio caesaria. Midcal Hospitalia, 2(2), 121. Retrieved from https://medicahospitalia.rskariadi.co.i d/index.php/mh/article/view/104

Fatikhah, A. \& Setiyowati, W. (2012). Hubungan tingkat kecemasan dan dukungan keluarga dengan lama persalinan kala I, 0, 1-17.

Husny. (2009). Pengaruh Aromaterpy Pada Persalinan. (N. L. Umaiyah, Ed.). Yogyakarta: PT Pustaka Baru.

Ilmiah, W. I. (2015). Asuhan Persalinan Normal (1st ed.). Yogyakarta: Nuha Medika.

Karlina, S.D., Reksohusodo, S. \& Widayati, A. (2014). Pengaruh Pemberian Aromaterapi Lavender secara Inhalasi terhadap Penurunan Intensitas Nyeri Persalinan Fisiologis pada Primipara Inpartu Kala Satu Fase Aktif di BPM "Fetty. Fakultas Kedokteran Universitas Brawijaya, 109.

Mufdlilah ., Hidayat, A. \& Kharimahturrahma, L. (2012). Konsep Kebidanan (1st ed.). Yogyakarta: Nuha Medika.

Nolan. (2013). Asuhan Persalinan Kebidanan. (W. Kristiyanasari, Ed.) (1st ed.). Yogyakarta: Nuha Medika. Rohani ., Saswita, R., \& M. (2011). Asuhan Kebidanan pada Masa Persalinan. (T. E. P. S. Medika, Ed.). Jakarta: Penerbit Salemba Medika.

Trirestuti, C. \& Puspitasari, D. (2018). Asuhan Kebidanan 2 (1st ed.). Jakarta: CV. Trans Info Media. 